\title{
Kajian Potensi dan Strategi Pengembangan Ekowisata Bahari Pulau Pagang, Kecamatan Koto XI Tarusan, Kabupaten Pesisir Selatan, Sumatera Barat
}

\author{
Study of the Potential and Development Strategies of Marine Ecotourism Pagang \\ Island Sub-District Koto XI Tarusan District Pesisir Selatan West Sumatera
}

\author{
Feri Handoyo Pardede ${ }^{1 *}$, Dessy Yoswaty $^{1}$, Aras Mulyadi ${ }^{1}$ \\ ${ }^{1}$ Jurusan Ilmu Kelautan, Fakultas Perikanan dan Kelautan, Universitas Riau \\ Kampus Bina Widya Jl. HR. Soebrantas Km 12.5, Pekanbaru, 28293 \\ email: ferihandoyo55@gmail.com
}

(Received: 10 Januari 2022; Accepted: 01 Maret 2022)

\begin{abstract}
ABSTRAK
Penelitian ini dilaksanakan Bulan Januari - Februari 2020 di Pulau Pagang, Kecamatan Koto Xi Tarusan, Kabupaten Pesisir Selatan, Sumatera Barat. Penelitian bertujuan untuk mengetahui potensi ekowisata bahari dan aspek yang menjadi kekuatan pada perairan Pulau Pagang untuk dikembangkan sebagai kawasan ekowisata bahari. Metode yang digunakan dalam penelitian ini adalah metode survei dan penentuan titik stasiun secara purposive sampling. Hasil perhitungan dari Nilai Indeks Kesesuaian Wisata yaitu 80,77\% (Stasiun I), 80,77\% (Stasiun II), 82,69\% dan (Stasiun III). Penilaian mengenai kekuatan, kelemahan, peluang, dan ancaman, pengembangan potensi perairan Pulau Pagang dinilai dari hasil pengamatan di lokasi penelitian, wawancara dan kuesioner. Pulau Pagang memiliki potensi sebagai kawasan ekowisata bahari seperti keindahan alam yang alami, terumbu karang, dan memiliki biota laut yang khas. Pengembangan obyek wisata bahari di Pulau Pagang dapat dilakukan dengan 1) Penataan wilayah dengan membentuk sistem zonasi untuk kegiatan wisata bahari dan kegiatan yang dilakukan masyarakat terhadap aktivitas ekowisata pantai dan pengelolaan lingkungan pesisir, 2) meningkatkan promosi berskala nasional maupun internasional, 3) Penyusunan tata ruang atau zonasi wisata dengan berbagai lembaga terkait dan masyarakat lokal.
\end{abstract}

Kata Kunci: Potensi, Ekowisata Bahari, Analisis SWOT, Pulau Pagang

\begin{abstract}
This research was conducted in January - February 2020 at Pagang Island Sub-District Koto Xi Tarusan District Pesisir Selatan West Sumatera. The study aims to determine the potential of marine ecotourism and aspects of the strength of Pagang Island to be developed as a marine ecotourism area. The method used in this research is survey method and station point determination by purposive sampling. Value The results of the calculation of the value of the index the suitability of the Tour amounted to $80,77 \%$ (Station I), $80.77 \%$ (Station II) and $82.69 \%$ (Station III). Assessment of strengths, weaknesses, opportunities, and threats, the development of Pagang Island coastal potential was assessed from observations at research sites, interviews and questionnaires. Pagang Island has the potential as a marine ecotourism area such as the beauty of nature and distinctive marine biota. The development of Marine Tourism in Penyengat island can be done with 1) The arrangement of the area by forming a system of zoning for marine tourism activities and the activities done by the society on the activity of the ecotourism beach and the management of the coastal environment, 2) improve the promotion of national and international scale; and 3) The preparation of spatial planning or zoning access with a variety of related institutions and local communities.
\end{abstract}

Keyword: Potential, Marine Ecotourism, SWOT Analysis, Pagang Island 


\section{Pendahuluan}

Ekowisata merupakan perjalanan wisata ke suatu lingkungan baik alam yang alami maupun buatan serta budaya yang ada yang bersifat informatif dan partisipatif yang bertujuan untuk menjamin kelestarian alam dan sosial-budaya (Yoswaty dan Samiaji, 2010).

Ekowisata menitikberatkan pada tiga hal utama yaitu; keberlangsungan alam atau ekologi, memberikan manfaat ekonomi, dan secara psikologi dapat diterima dalam kehidupan sosial masyarakat, dengan begitu kegiatan ekowisata secara langsung memberi akses kepada semua orang untuk melihat, mengetahui, dan menikmati pengalaman alam, intelektual dan budaya masyarakat lokal (Armos, 2013) .

Pulau Pagang adalah pulau yang indah yang ada di salah satu provinsi sumatera barat yang terletak di pesisir laut pulau sumatera. Pesisir selatan menyimpan berbagai kekayaan alam yang luar biasa mulai sektor pariswisata yang belum tergali potensinya karena kurangnya informasi-informasi mengenai tempat-tempat wisata yang berada di pesisir selatan

\section{Metode Penelitian}

\subsection{Waktu dan Tempat}

Penelitian ini dilaksanakan bulan Januari - Februari 2020 di Pulau Pagang, Kecamatan Koto Xi Tarusan, Kabupaten Pesisir Selatan, Sumatera Barat (Gambar 1).

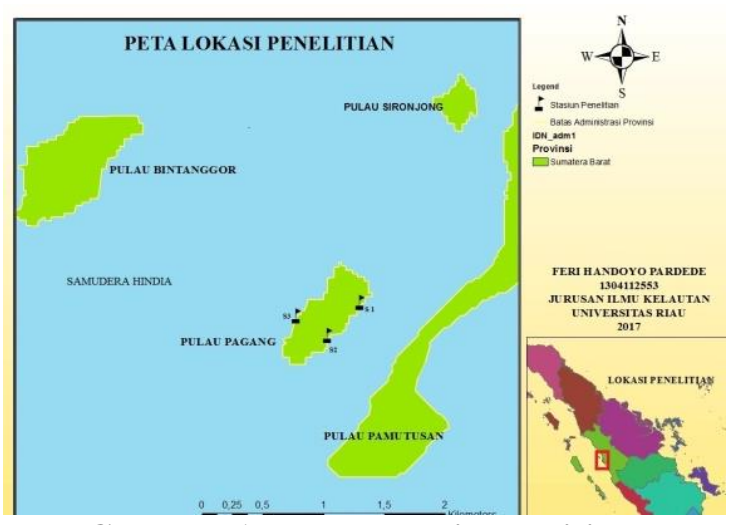

Gambar 1. Peta Lokasi Penelitian

\subsection{Metode Penelitian}

Metode yang digunakan dalam penelitian ini adalah metode survei, untuk penempatan stasiun dilakukan dengan metode purposive sampling, yang terdiri atas 3 titik sampling. Pemilihan sampel untuk wawancara dilakukan dengan metode purposive sampling. Responden dipilih dalam penelitian ini yaitu responden masyarakat lokal, wisatawan, pelaku usaha dan pemangku kebijakan (Yulianda, 2007).

\section{Hasil dan Pembahasan}

\subsection{Kondisi Umum Lokasi Penelitian}

Pulau Pagang terletak di Kecamatan Koto

$\mathrm{Xi}$ Tarusan, Kabupaten Pesisir Selatan, Sumatera Barat, dengan posisi geografis pulau terletak pada koordinat $01^{\circ} 09^{\prime} 34^{\prime \prime}$ LS dan $100^{\circ} 20^{\prime} 55^{\prime \prime}$ BT. Pulau ini memiliki luas 2,47 $\mathrm{km}^{2}$. Pulau Pagang dapat ditempuh melalui jalur laut dengan perahu nelayan atau perahu wisata, akses ke pulau ini dapat melalui dua wilayah, yaitu; melalui kota Padang dapat ditempuh melalui pelabuhan Bungus $15 \mathrm{Km}$ dengan waktu tempuh 30 menit, dan melalui Kabupaten Pesisir Selatan dari Sungai Pinang $7 \mathrm{~km}$ dengan waktu tempuh 10 menit.

Kualitas perairan Pulau Pagang berkisar antara 0,15- 0,19 $\mathrm{m} /$ detik, kecerahan berkisar 4-6 meter, sedangkan suhu berkisar antara 29$30{ }^{\circ} \mathrm{C}$, salinitas perairan berkisar $29-30 \mathrm{ppt}$, pH perairan 7 dan kedalaman tiap stasiun 4-6 meter.

\subsection{Potensi Perairan Pagang}

Pulau Pagang memiliki perairan yang sangat jernih, dimana dasar perairan dapat dilihat dari permukaan perairan, selain bermain air dapat juga untuk kegiatan lainnya seperti snorkeling untuk melihat keindahan bawah laut pulau pagang seperti melihat ikan berenang di terumbu karang yang indah. Selain itu ada juga permainan air seperti banana boat yang dapat membuat pengunjung mendapatkan tantangan bermain air lainnya.

Pulau Pagang memiliki pantai yang landai bersubstrat pasir putih yang halus dan memiliki perairan yang jernih hingga kelihatan dasar perairannya yang menunjang untuk diadakannya ekowisata bahari. Hal ini terlihat dari hasil penelitian tentang kesesuaian lahan tiap stasiun dimana rata-rata kedalaman yang ditemukan berkisar 1,4-2,4 meter dan termasuk ke dalam syarat yang paling sesuai untuk wisata pantai dan aktifitas lainnya. 


\subsection{Pelaku Usaha Pulau Pagang}

Masyarakat dapat menjadi pelaku usaha, penyedia jasa, dan menjadi subjek pendukung dengan adanya kegiatan ekowisata diwilayahnya. Hasil analisis responden untuk masyarakat lokal dapat dilihat pada Gambar 2.

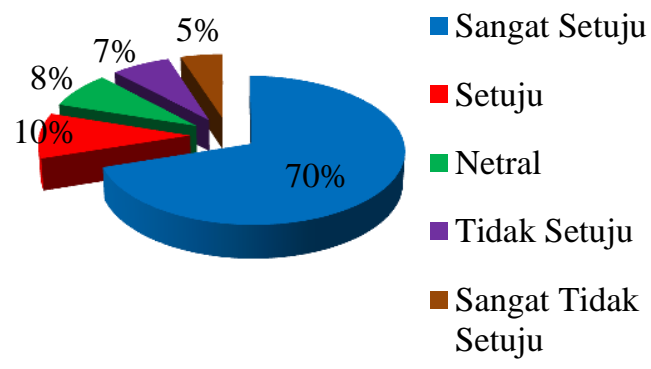

\section{Gambar 2. Diagram Masyarakat Lokal}

Dari hasil persepsi untuk kategori masyarakat lokal dapat disimpulkan bahwa masyarakat lokal lebih dominan mendukung dikembangkannya potensi Pulau Pagang sebagai kawasan ekowisata bahari, dengan persentase responden mencapai $70 \%$ sangat setuju untuk dikembangkan Pulau Pagang.

Wisatawan yang berkunjung di Pantai Pagang terdiri dari wisatawan lokal dan wisatawan mancanegara. Jumlah wisatawan yang berkunjung ke Pulau Pagang dari hasil wawancara kepada masyarakat lokal dan dinas pariwisata jumlah wisatawan yang berkunjung adalah \pm 100.000 orang per tahun. Persepsi wisatawan terhadap pengembangan potensi ekowisata bahari Pulau Pagang, dapat dilihat pada Gambar 3.

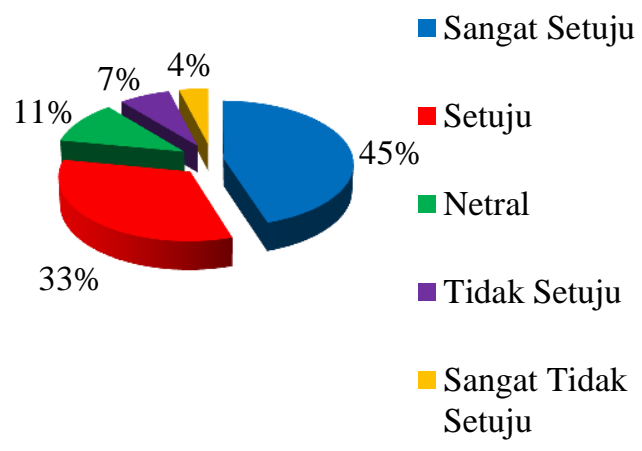

\section{Gambar 3. Diagram Wisatawan}

Dari gambar diatas, dapat disimpulkan bahwa wisatawan sangat mendukung Pulau Pagang untuk dikembangkan ekowisata bahari agar dapat dikeluarkan potensinya secara maksimal, berbanding terbalik dengan yang tidak setuju dikarenakan hanya sedikit dengan persentase $45 \%$ sangat setuju untuk dikembangkan wisata Pulau Pagang.

Pelaku usaha wisata di Pulau Pagang terdiri dari masyarakat lokal itu sendiri. Usaha yang ditawarkan kepada wisatawan masih terlalu minim hanya terdiri dari jasa penyedia transportasi untuk memancing dan berkeliling di sekitar perairan Pulau Pagang, penjual makanan dan minuman. Persepsi pelaku usaha terhadap pengembangan potensi pantai Pulau Pagang sebagai kawasan ekowisata bahari, dapat dilihat pada Gambar 4.

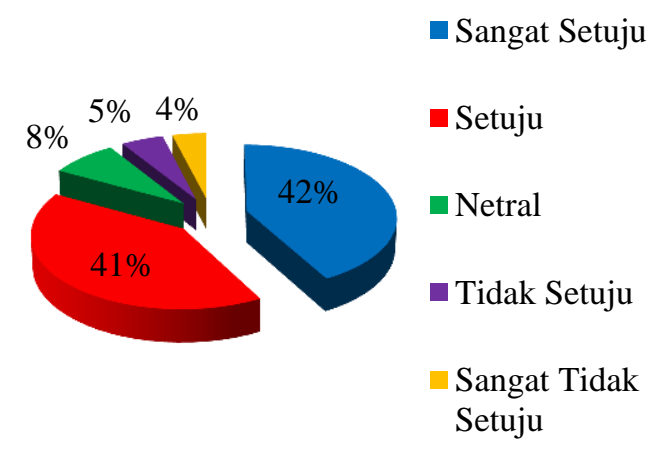

\section{Gambar 4. Diagram Pelaku Usaha}

Berdasarkan Gambar 4 persepsi pelaku usaha menunjukkan bahwa $42 \%$ pelaku usaha yang diwawancarai mengatakan sangat setuju dilakukannya pengembangan potensi kawasan ekowisata bahari di Pulau Pagang. Dari hasil persepsi untuk kategori pelaku usaha dapat disimpulkan bahwa pelaku usaha lebih dominan mendukung dikembangkannya potensi Pulau Pagang sebagai kawasan ekowisata bahari.

Pemangku kebijakan memiliki peran penting dalam pengembangan potensi ekowisata bahari di Pulau Pagang dengan cara mendukung dan menfasilitasi masyarakat setempat. $66 \%$ pemangku kebijakan yang diwawancarai mengatakan sangat setuju dilakukannya pengembangan potensi kawasan ekowisata bahari di Pulau Pagang. Dari hasil persepsi untuk kategori pemangku kebijakan dapat disimpulkan bahwa pemangku kebijakan lebih dominan mendukung dikembangkannya potensi Pulau Pagang sebagai kawasan ekowisata bahari. Adapun persepsi pemangku kebijakan terhadap pengembangan potensi ekowisata Pulau Pagang ini dapat dilihat pada Gambar 5. 


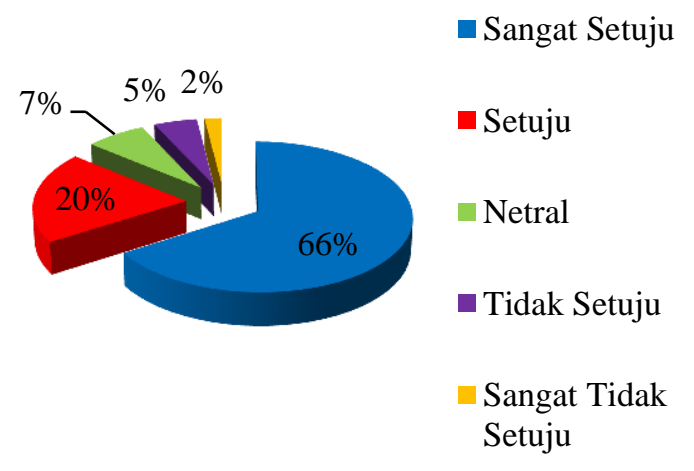

Gambar 5. Pemangku Kebijakan

Kondisi sumberdaya alam yang terdapat di Pulau Pagang dari hasil pengamatan dilapangan berada dalam kondisi yang baik. Ini sesuai dengan hasil wawancara di lapangan dan mayoritas mengatakan kondisi pantainya berada dalam kondisi yang sangat baik dan sangat setuju diadakan ekowisata bahari di Pulau Pagang. Pelaku usaha di Pulau Pagang dan sekaligus masyarakat lokalnya sangat setuju dilakukan pengembangan ekowisata bahari di Pulau Pagang dan masyarakat lokal maupun pelaku usaha sangat menjaga keaslian sumberdaya alam pulau ini agar ekowisatanya dapat dinikmati hingga watu yang sangat lama.

\subsection{Indeks Kesesuaian Wisata}

Analisis IKW diperlukan untuk melihat apakah kawasan wisata pantai Pulau Pagang memenuhi standar untuk wisata pantai. Kriteria kesesuaian wisata untuk wisata pantai disajikan pada Tabel 1.

Tabel 1. Indeks Kesesuaian Wisata

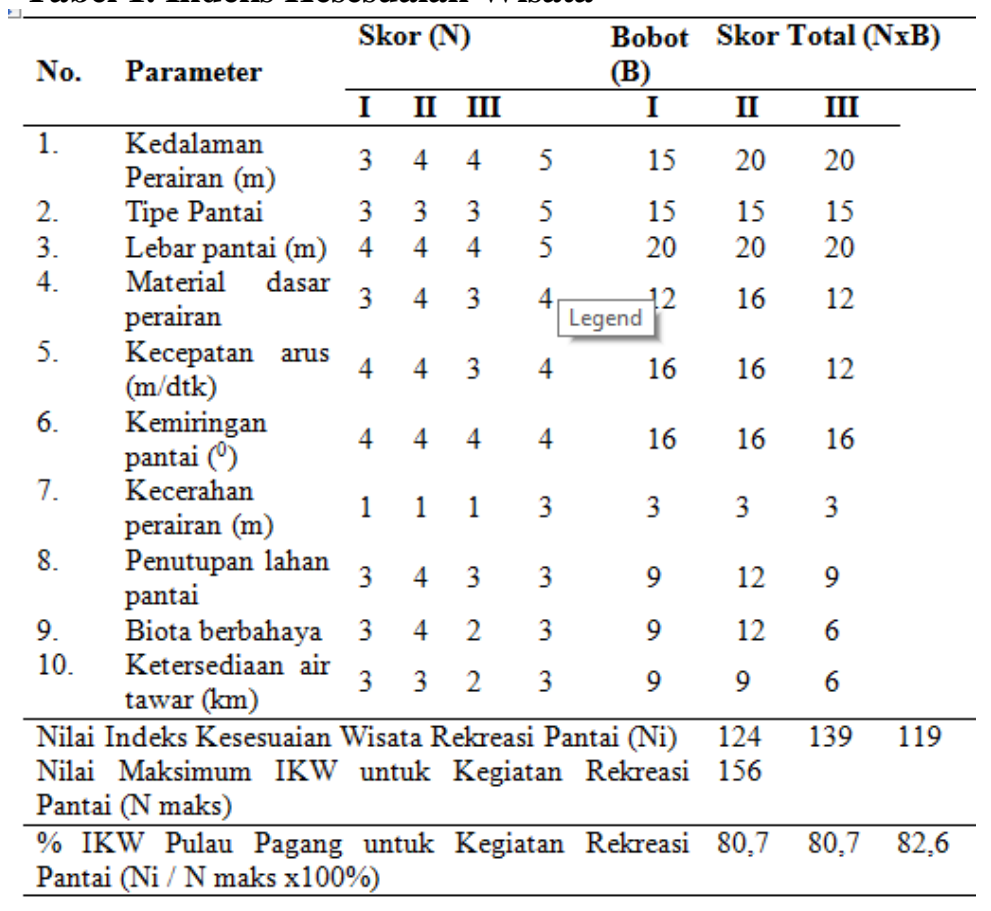

Tabel 1 menunjukkan bahwa nilai Indeks Kesesuain Wisata yang paling tinggi yaitu pada Stasiun III yaitu bernilai 82,69\%, kemudian disusul Stasiun I dan II yang bernilai $80,77 \%$, termasuk kedalam kategori sangat sesuai sebagai wisata rekreasi pantai.

Penentuan kesesuaian melalui analisa kesesuaian lahan berasal dari perkalian skor dan bobot yang diperoleh dari setiap parameter pada tiap jenis kegiatan wisata. Kesesuaian lahan ini dilihat dari persentase kesesuaian yang diperoleh dari nilai total seluruh parameter kesesuaian tiap jenis kegiatan wisata.

Lokasi Stasiun I, II dan III memiliki persentase kesesuaian lahan yang termasuk ke dalam kategori S1 yang artinya wilayah ini sangat sesuai untuk dikembangkan sebagai lokasi kegiatan rekreasi perairan pantai. Kegiatan wisata yang akan dikembangkan hendaknya disesuaikan dengan potensi sumberdaya dan peruntukkannya. Setiap kegiatan wisata mempunyai persyaratan sumberdaya dan lingkungan yang sesuai objek 
wisata yang akan dikembangkan. Parameter indeks kesesuaian wisata dalam penelitian ini meliputi tipe pantai, lebar pantai, material dasar perairan, kemiringan pantai, penutupan lahan pantai, kedalaman perairan, kecepatan arus, tinggi gelombang, kecerahan perairan, biota berbahaya dan ketersediaan air tawar (Yoswaty dan Samiaji, 2010).

Nilai rata-rata WTA untuk suatu kegiatan wisata bahari Pulau Pagang yang diajukan oleh masyarakat setempat yang berperan sebagai pelaku usaha senilai Rp. 53.000 . Sementara nilai rata-rata WTP untuk suatu kegiatan wisata di Pulau Pagang yang dapat dibayar oleh wisatawan adalah senilai $\mathrm{Rp}$. 58.000. Dari hasil tersebut,dapat dilihat bahwa nilai WTA rata-rata lebih rendah dibanding nilai WTP rata-rata. Hal ini menunjukkan bahwa kesediaan wisatawan untuk membayar jauh lebih tinggi dibandingkan dengan nilai yang diharapkan oleh masyarakat atau pelaku usaha.

Potensi ekonomi wisata Pulau Pagang dapat diketahui dengan cara melihat nilai ratarata WTP per individu dikali dengan jumlah total kunjungan wisatawan yang datang ke lokasi. Hasil potensi ekonomi wisata yang didapat sebesar Rp. 5.800.000.000. Hasil tersebut menunjukkan nilai ekonomi yang didapat dalam setiap tahunnya berpotensi meningkatkan kesejahteraan masyarakat lokal.

\section{Kesimpulan dan Saran}

Nilai indeks kesesuaian wisata di Pulau Pagang stasiun I $(80,77 \%)$, II $(80,77 \%)$, III $(82,69 \%)$. Berdasarkan indeks kesuaian wisata, Pulau Pagang termasuk dalam kategori S1 (sangat sesuai), dimana keempat stasiun penelitian tersebut sangat sesuai untuk dikembangkan sebagai kawasan ekowisata bahari. Bagian tepi pantai dapat ditambahkan tempat untuk bersantai agar wisatawan dapat menikmati keindahan pantai dengan leluasa.

Untuk pemangku kebijakan perlu membuat peraturan pengelolaan ekowisata bahari, zona, pelaku, sarana, retribusi, diatur dengan lebih maksimal. Diperlukannya menyiapkan SDM yang terampil dan berwawasan melalui berbagai pelatihan. Menciptakan lokasi yang aman, bersih, nyaman dan aman untuk kawasan ekowisata bahari di Pulau Pagang. Diperlukan penelitian lanjutan untuk dapat mengeluarkan potensi ekowisata bahari di Pulau Pagang agar dapat menjadi ekowisata bahari yang berkelanjutan.

\section{Daftar Pustaka}

Armos, N.H. (2013). Studi kesesuaian Lahan Pantai Wisata Boe Desa Mappakalompo Kecamatan Galesong Ditinjau Berdasarkan Biogeofisik. Skripsi. Fakultas Ilmu Kelautan dan Perikanan. Universitas Hasanuddin. Makassar.

Damanik, J., dan Weber, H.F. (2006). Perencanaan Ekowisata. PUSPAR UGM dan Andi, Yogyakarta.

Hariyana, K. (2015). Persepsi Masyarakat Terhadap Pengembangan Kawasa Goa Peteng sebagai Daya Tarik Wisata di Desa Jimbaran Kuta Selatan Kabupaten Badung. Jurnal Destinasi Pariwisata, 3 (1): 24 - 34.

Sugianto, D. N., Agus, A.D.S. (2007). Studi Pola Sirkulasi Arus Laut di Perairan Pantai Provinsi Sumatera Barat. Jurnal. Ilmu Kelautan, 12 (2) :79-92.

Yoswaty, D. dan Samiaji, J. (2010). Buku Ajar Ekowisata Bahari. UR Press, Riau. 111 hlm.

Yulianda, F. (2007). Ekowisata Bahari sebagai Alternatif Pemanfaatan Sumberdaya Pesisir Berbasis Konservasi. Bogor. MSP - FPIK IPB 